\title{
A Model to Evaluate the Thermal Conductivity of the Coral Reef in Tahiti
}

\author{
Alessio Guarino ${ }^{1,2}$ \\ ${ }^{1}$ Laboratoire de Physique de l'Ecole Normale Supérieure de Lyon, Université de la Polynésie Française, Faa'a, Tahiti, \\ 98702 Polynésie Française, France \\ ${ }^{2}$ Université de la Méditerranée (Aix-Marseille II), 13284 Marseille Cedex 7, France
}

Correspondence should be addressed to Alessio Guarino, alessio.guarino@univmed.fr

Received 5 September 2010; Revised 4 January 2011; Accepted 4 February 2011

Academic Editor: Steven Sherwood

Copyright (๑) 2011 Alessio Guarino. This is an open access article distributed under the Creative Commons Attribution License, which permits unrestricted use, distribution, and reproduction in any medium, provided the original work is properly cited.

Ohm's law models have been used in several works in geophysical prospecting but have never been used for coral reef. We adapted such a model to the barrier reef of Papeete (Tahiti island) in order to estimate of its thermal conductivity. We found the thermal conductivity of the barrier reef is about four times greater than that of the water. The results are then validated by the mean of experimental measurements.

\section{Introduction}

The circulation of the interstitial water within the porous media of a coral reef is important for islands located in oligotrophic ocean. Indeed, the rich environment (fauna and flora) of these islands can be explained by nutrient input to the area by an upwelling process within the reef, a process called the endoupwelling [1-3]. In this process, vertical movement of water within the reef is expected, and evidence by measurements is missing because of the slow vertical movement of the water [4]. To date, clear evidence of the vertical movement of water in coral reef is only shown by models [5]. The models developed to study the circulation of interstitial waters inside coral reefs are based on Darcy's law and the continuity equation and generally are adapted to a two-dimensional reef [6]. In order to describe the endoupwelling process, the heat equation has to be considered and must include all heat transfer such as conduction, convection, and dispersion in the fluid and heat exchange between the solid media and the fluid. Use of the heat equation requires a priori knowledge of the thermal conductivity and the heat capacity of the medium which in our case is a saturated porous medium.

In situ measurement of thermal conductivity is impossible to achieve within a bore well [7]. Determination of the thermal conductivity are carried out in the laboratory, and using empirical relationship, the thermal conductivity of the matrix is calculated. Methods to determine thermal conductivity of saturated porous media are indirect and often make use of models. From the temperature field data, thermal conductivity can be assessed by Fourier's law models, Ohm's law models, or by empirical model. Samaden et al. [8] used Darcy's law, the continuity equation, and the heat equation to develop a semiempirical multilayer model of the Eniwetak atoll. They estimated the thermal conductivity of the Eniwetok atoll to be between 2.5 to $5 \mathrm{~W} /(\mathrm{mK})$. Application of the Fourier's law model requires an idealized geometry, and extrapolation to the randomly packed medium is needed. For Ohm's law models, repetitive geometries are assumed to be representative of the randomly packed medium. An equivalent electrical network is developed, and the thermal conductivity of the system is obtained from the thermal-electrical analogy [9]. The Ohm's law model, which has been used in several works in geophysical prospecting [10], has never been used for coral reef, and, here, we adapted such a model to the coral reef of Papeete.

In this paper, our focus is to determine the thermal conductivity of the barrier reef of Papeete by developing an Ohm's law model. For such a model, vertical temperature profiles are needed. We used collected data from the coral 

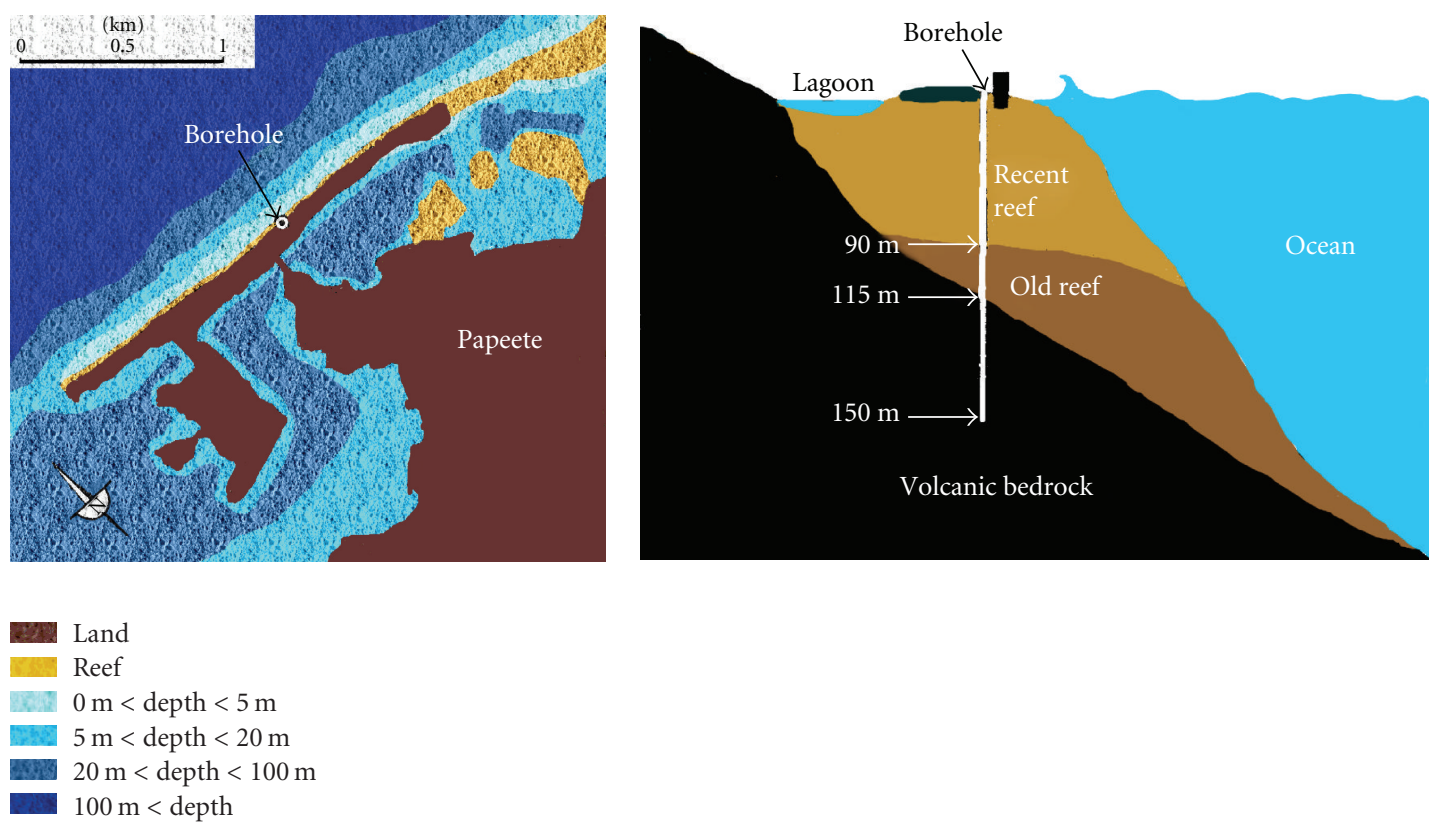

(a)

(b)

FIgURE 1: Top view (a) of the site with the bathymetry and reef. Vertical structure in the reef (b).

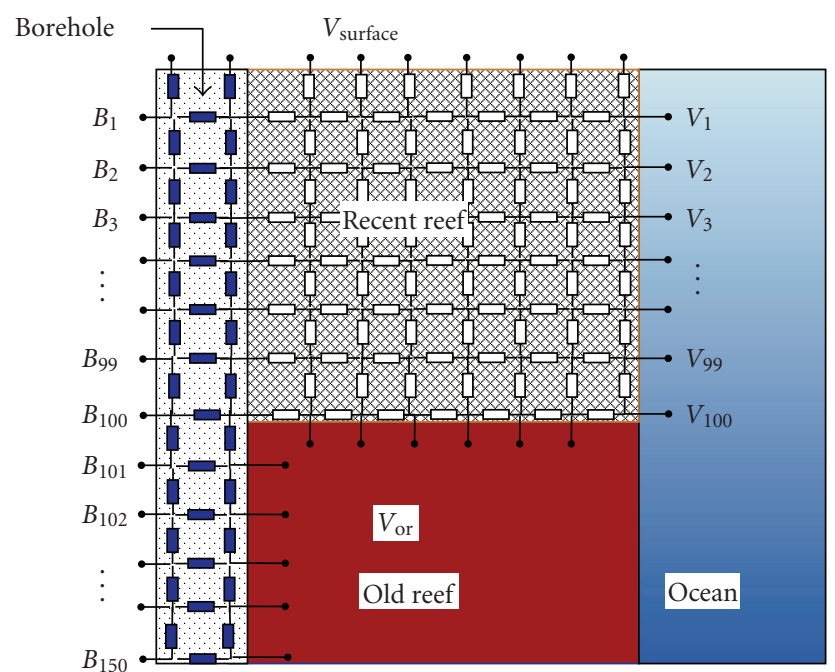

FIGURE 2: Simple schematization of the electrical network used for the simulation. The white conductances represents the thermal conductivity of the system reef plus water $\left(\lambda_{\mathrm{rw}}\right)$ while the dark ones represent the thermal conductivity of the borehole water $\left(\lambda_{\mathrm{w}}\right)$. In the model, the actual geometry of the system is respected.

reef in Tahiti. The electrical model analogy is then developed followed by the presentation of our results and discussions.

\section{Site and Data}

The site location is shown on Figure 1. A well was dug into the Papeete (17.24 S, 149.36 W) reef during the "Endoupwelling program" field campaign [11]. Study of the vertical

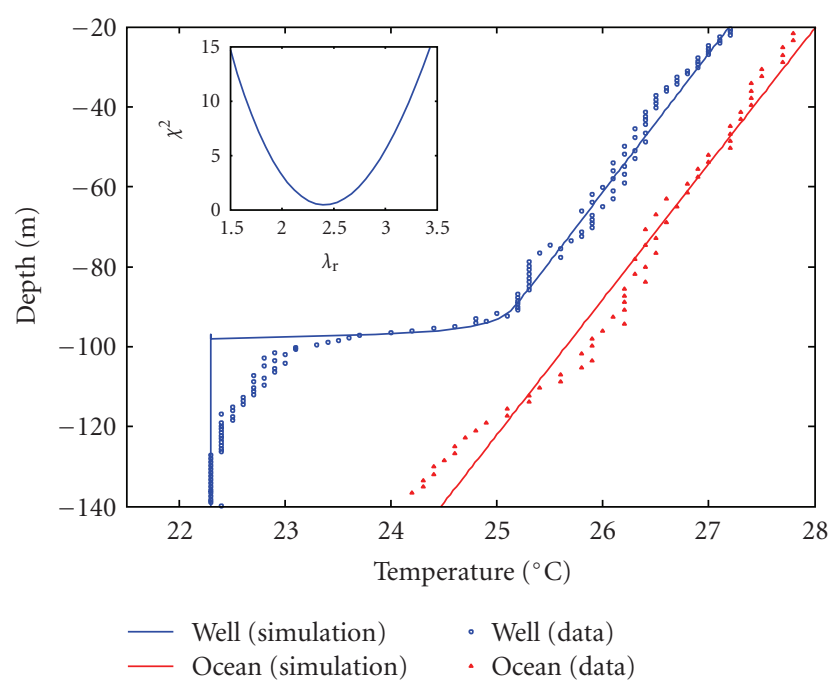

Figure 3: Temperature in the well (blue dot) and in the ocean (red dot) and idealized profile used in the analogical model. In the inset, Pearson's chi-square as a function of the thermal conductivity of the recent reef $\lambda_{\mathrm{r}}$. The minimum of the curve, $\lambda_{\mathrm{r}}=2.4 \mathrm{~W} /(\mathrm{mK})$, corresponds to the best fit.

structure showed that the top $150 \mathrm{~m}$ of the reef could be divided in three regions: the carbonate reef on top, the bedrock at the bottom, and the old reef in between [11]. Temperature profiles have been measured in the borehole and in the ocean nearby during March and June 1993 with an Aanderaa CTD, and data were collected every meter within the $150 \mathrm{~m}$ water column. Measurement of the temperature of the old reef shows a constant vertical temperature $\left(22.1^{\circ} \mathrm{C}\right)$ profile. 
Analysis of individual profile shows that the first ten meters of the water column appreciably change between these two months. This is expected near the surface where daily influence of the atmospheric conditions is important. On Figure 3, we report the average temperature profiles. The vertical temperature profile in the ocean shows a linear decrease with depth. Lower in general than in the ocean, the temperature in the borehole linearly decreases in the carbonate reef (recent reef, first $90 \mathrm{~m}$ ) and decreases rapidly to reach a constant value of $22.3^{\circ} \mathrm{C}$.

\section{Model}

The Ohm's law model based on thermal-electrical analogy is used to determine the thermal conductivity. The density of electrical current $J$, the electrical conductivity $\lambda_{\text {ohm }}$, and voltage $V$, which are related by the Ohm's law $\vec{J}=\lambda_{\text {ohm }} \vec{\nabla} V$, are analogous, respectively, to the heat flux $\phi$, the thermal conductivity $\lambda$, and the temperature $T$, parameters that are linked by Fourier's law $\vec{\Phi}=\lambda \vec{\nabla} T$. In order to simplify the model, we used a coarse grained description of the system which takes into account the geometry of the system. We divided the system into cubic cells of size $L$. Assuming that the density of electrical current $J$ varies slowly in space (the temperature gradient is of the order $0.05 \mathrm{~K} / \mathrm{m}$ ), we can use "concentrated" variables $I$ and $\Delta V$, corresponding, respectively, to the electric current and potential difference over the cell size $L$. In this case, $J$ can be roughly represented as $J=I / L^{2}$. The ocean is considered as a thermostat, and its temperature field is modeled with a series of ideal $n$ voltage generators $V_{n}$ (with $n=1$ to 150). For instance, the ocean temperature measured at depth $n$ meters is modeled by a constant voltage generator set at $V_{n}=T_{n} V$. The temperature of the water at the free surface $V_{\text {surface }}$ is considered constant. Because its constant vertical temperature profile, the temperature of the old reef, is held at $22.1 \mathrm{~V}$ (i.e., $22.1^{\circ} \mathrm{C}$ ). The ocean and the recent reef are connected to the water in the well by a square network of conductances $\lambda_{\mathrm{rw}}$ whose value represents the thermal conductivity of the system reef plus water $\left(\lambda_{\mathrm{rw}}=\lambda_{\mathrm{r}}+\lambda_{\mathrm{w}}\right)$, Figure 2 . The water in the well is modeled by a square network of conductances $\lambda_{\mathrm{w}}$ that represent the thermal conductivity of the water, Figure 2. The thermal conductivities $\lambda_{\mathrm{r}}$ and $\lambda_{\mathrm{w}}$ were assumed constant in the system, that is, we neglect their dependence on the depth and the temperature. The measured temperature profiles were used to set the values of the voltage (temperature) fields of the ocean $V_{n}$ and the old reef $V_{\text {or }}$. The value of $\lambda_{\mathrm{r}} / \lambda_{\mathrm{w}}$ was optimised to generate a temperature field in the well closest to the measured data.

\section{Results and Discussions}

Our analysis has been done only with data taken during good weather conditions, that is, under normal swell. In this case, the temperature profiles measured in the well and the ocean always show the same features. We only notice a shift on the temperature value, Figure 3. This is both due to the atmospheric conditions and the sun cycle. The mixing due to the surface waves, and the boundary layer of the waterair interface affect only the first $10-15 \mathrm{~m}$ of the temperature profile. In order not to take in account these effects, which are negligible for the aim of our study, we only considered data taken below $20 \mathrm{~m}$.

The ocean temperature decreased linearly with depth. The well's temperature profile is more complex. It can be considered linear with depth within the layer of the recent reef ( down to $100 \mathrm{~m})$. The temperature in the well decreased linearly with depth within the recent reef layer ( down to $100 \mathrm{~m}$ ), before a sharp decrease to a constant value of $22^{\circ} \mathrm{C}$. This indicates that interstitial water mixes well with the ocean water within the layer of the recent reef and that it is isolated from the influence of oceanic water within the old reef. We performed our analysis over more than 200 vertical temperature profiles, and we found that $\lambda_{\mathrm{r}} / \lambda_{\mathrm{w}}=4.0 \pm 0.8$. The thermal conductivity of the recent reef is, therefore, much greater than the thermal conductivity of the water. Therefore, $\lambda_{\mathrm{r}}=2.4 \pm 0.4 \mathrm{~W} /(\mathrm{mK})$, if one considers that the thermal conductivity of water under condition is $\lambda_{\mathrm{w}}=0.6 \pm 0.1 \mathrm{~W} /(\mathrm{mK})$. This value is in agreement with the empirical model of Samaden et al. [8] and fits in the range of conductivity of most parts of rocks [10].

\section{Conclusions}

The conclusion of our analysis is that the thermal conductivity within the recent reef is four times higher than the thermal conductivity of the water, which it is not a favorable condition for thermal convection [12]. Thus, conditions are not favorable for thermal convection during our period of investigation, coherently with the vertical temperature gradient. This gradient might, however, be modified under abnormal swell conditions. This might explain the enrichment in nutrients of the surface water. Another explanation might be convection due to the salinity gradient.

\section{Acknowledgments}

The authors thank Keitapu Maamaatuaiahutapu for helpful suggestions and enlightening discussions and Chiara for the endless sleepless nights.

\section{References}

[1] C. Andrié, P. Jean-Baptiste, C. Pierre et al., "Pore water geochemistry and mixing processes within the Tahiti barrier reef," Geochimica et Cosmochimica Acta, vol. 62, no. 16, pp. 2809-2822, 1998.

[2] F. Rougerie and B. Wauthy, "Le concept d'endo-upwelling dans le fonctionnement des atolls-oasis," Oceanologica Acta, vol. 2, pp. 133-148, 1986.

[3] F. Rougerie and B. Wauthy, "The endo-upwelling concept: from geothermal convection to reef construction," Coral Reefs, vol. 12, no. 1, pp. 19-30, 1993.

[4] J. A. Oberdorfer and R. W. Buddemeier, "Coral-reef hydrology: field studies of water movement within a barrier reef," Coral Reefs, vol. 5, no. 1, pp. 7-12, 1986. 
[5] A.-M. Leclerc, Modélisation des écoulements dans le milieu interstitiel corallien et quantification des échanges de matière avec l'environnement océanique, Thèse Doctorat, Ecole Nationale Supérieure des Mines, Paris, France, 1998.

[6] G. S. Kell, "Thermodynamic and transport properties of fluid water," in Water A Comprehensive Treatise, F. Franks, Ed., vol. 1, pp. 363-412, Plenum Press, New York, NY, USA, 1972.

[7] A. Hartmann, V. Rath, and C. Clauser, "Thermal conductivity from core and well log data," International Journal of Rock Mechanics and Mining Sciences, vol. 42, no. 7-8, pp. 10421055, 2005.

[8] G. Samaden, P. Dallot, and R. Roche, "Atoll d'Eniwetok. Système géothermique insulaire à l'état naturel," Houille Blanche, vol. 40, no. 2, pp. 143-151, 1985.

[9] Y. Ma, B. Yu, D. Zhang, and M. Zou, "A self-similarity model for effective thermal conductivity of porous media," Journal of Physics D: Applied Physics, vol. 36, no. 17, pp. 2157-2164, 2003.

[10] T. Madden, "Transmission Systems and Network Analogies to Geophysical Forward and Inverse Problems,” Tech. Rep., MIT, 1972.

[11] C. Andrié, I. Bouloubassi, H. Cornu, R. Fichez, C. Pierre, and F. Rougerie, "Chemical and tracer studies in coral reef interstitial waters (French Polynesia): implications for endoupwelling circulation," in Proceedings of the 7th Coral Reef International Symposium Guam, R. H. Richmond, Ed., pp. 1165-1173, University of Guam Press, 1993.

[12] L. E. Howle, "The effect of boundary properties on controlled Rayleigh-Benard convection," Journal of Fluid Mechanics, vol. 411, pp. 39-58, 2000. 

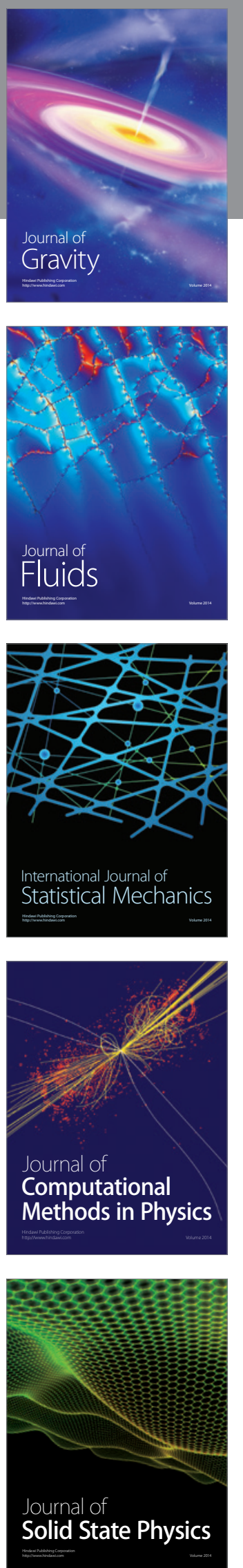

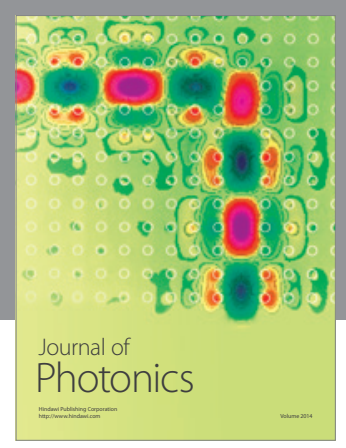

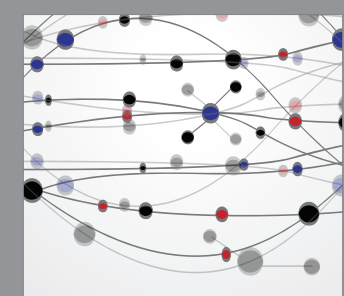

The Scientific World Journal
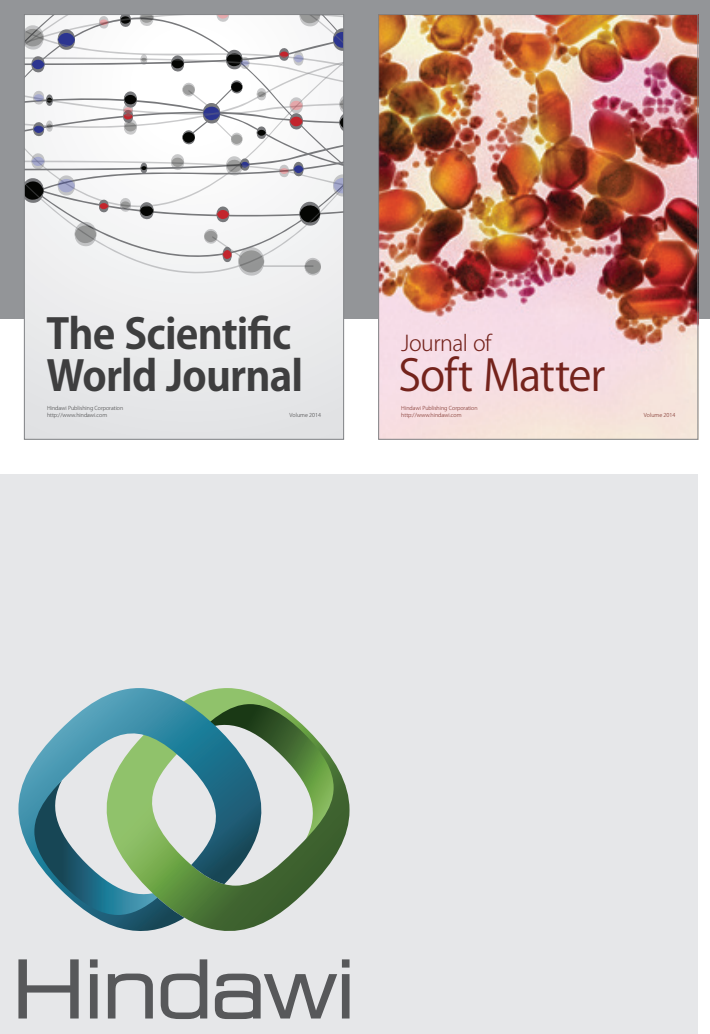

Submit your manuscripts at

http://www.hindawi.com
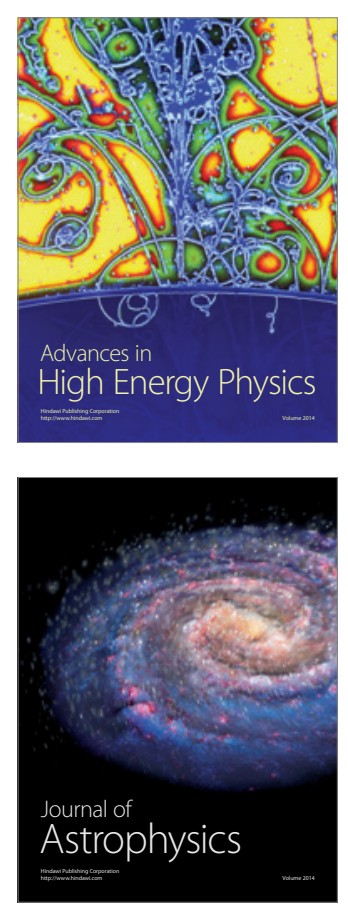
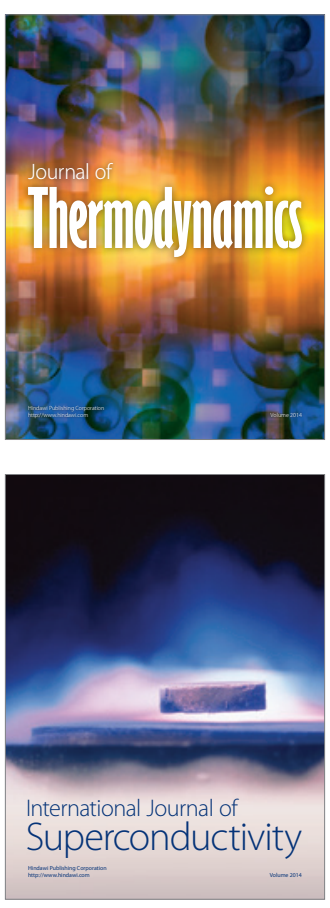
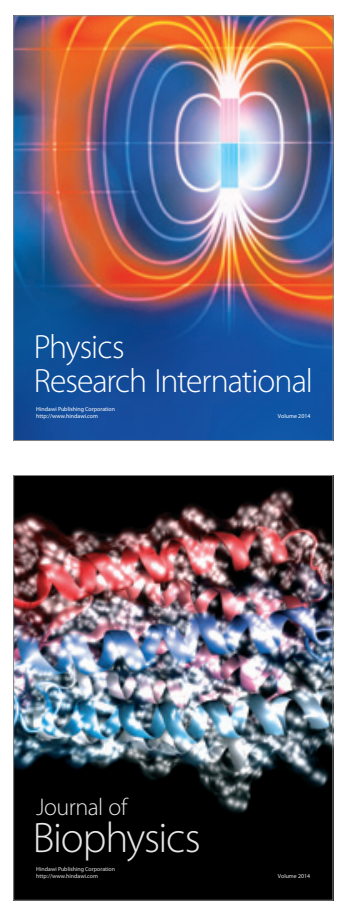
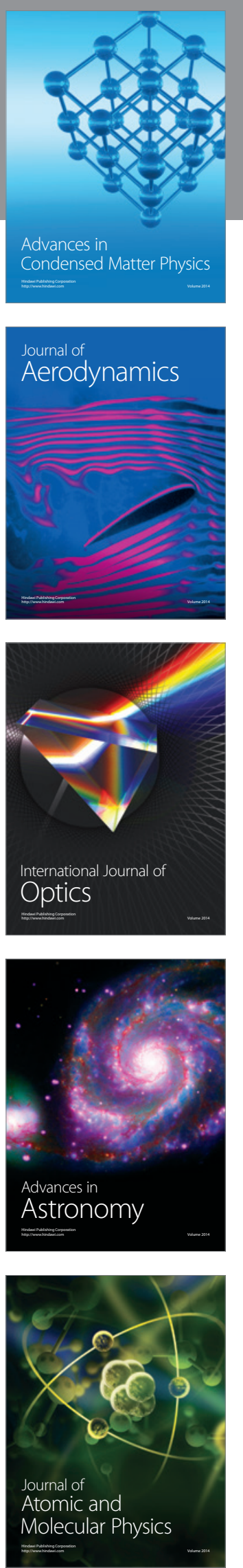